\title{
RUPTURED INTERVENTRICULAR SEPTA WITH SURVIVAL FOR SEVERAL DAYS
}

BY

\author{
GWYNETH HAMILTON, IDRIS JONES, AND A. G. STUART
}

From Harefield Hospital, Middlesex

Case 1. A woman, aged 70, was admitted with severe rheumatoid arthritis. She had been given butazolidin outside and had developed generalized œdema with shortness of breath.

On admission she was breathless, even at rest, with marked œdema of the legs and back and bilateral pleural effusions. The heart was enlarged to the left, the apex rate 100 and regular, and the blood pressure 210/90; there was a soft apical systolic murmur. She had a diffuse polyarthritis affecting practically all the joints of the body. She was kept at complete rest in bed and given physiotherapy for her joints. Her blood count at this stage was: hæmoglobin 67 per cent; red blood corpuscles 4,400,000; white blood corpuscles 13,800 with a normal differential count. Blood sedimentation rate $69 \mathrm{~mm}$. There was a moderate response to mersalyl but her joint condition remained almost unchanged, her main complaint being of pain in the knees. The œdema of the legs gradually increased but the heart signs remained static.

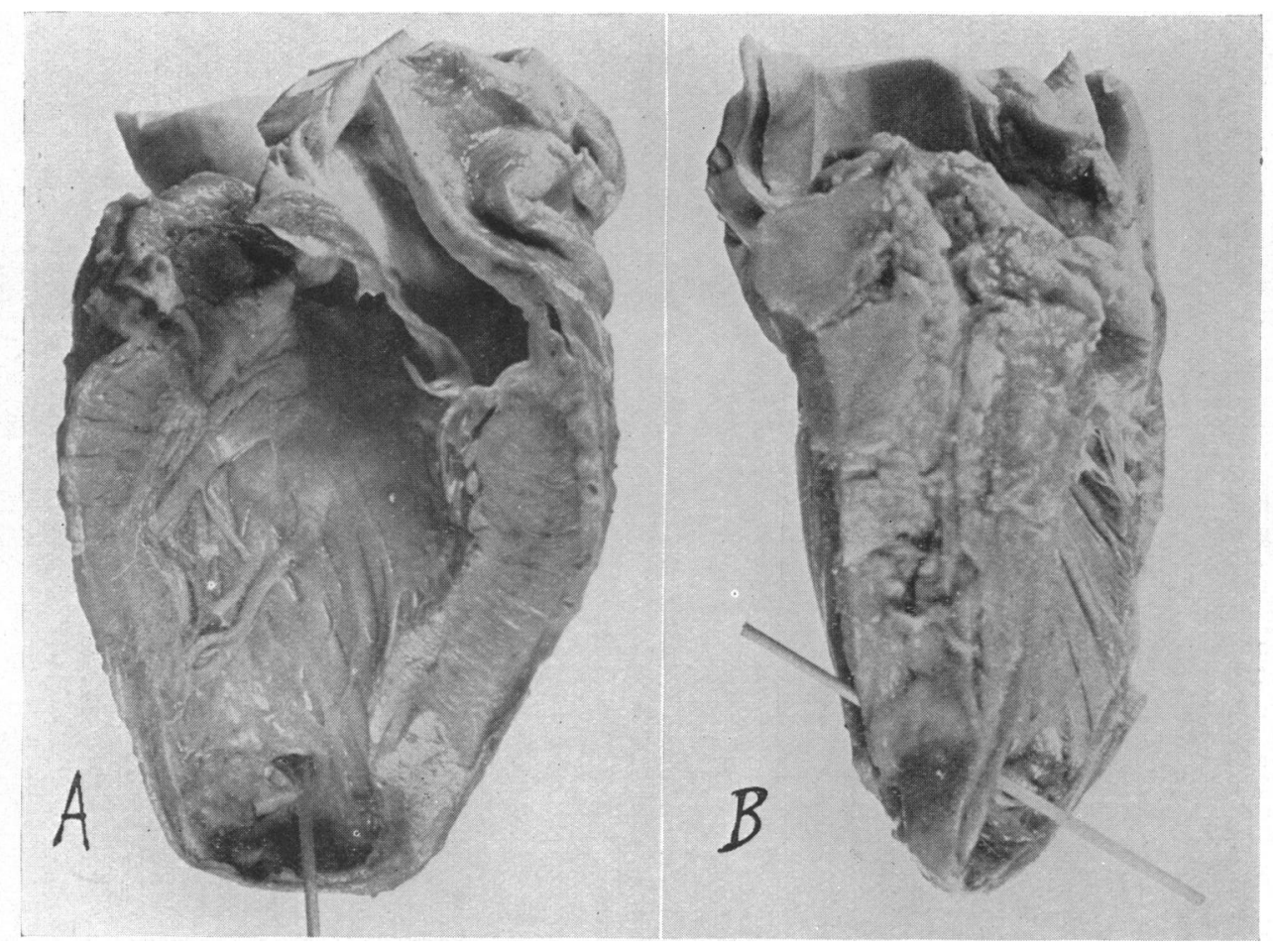

Fig. 1.-The heart: (A) from the left ventricle and (B) laterally. The perforation through the septum is marked by a probe. 
One morning, when she had been in hospital for five months, it was found, during a routine examination, that she had an intensely loud systolic murmur, audible all over the heart and maximal at the apex, and a palpable thrill. She had had no symptoms previously to make one suspect that anything untoward had happened; there had been no pain and no dyspnoea, the pulse rate was unaltered, and there had been no rise in temperature. The intensity of the murmur made one consider the diagnosis of ruptured interventricular septum. She became gradually more congested and died quietly fifteen days later.

Necropsy. The parietal pericardium was thickened, and adherent to the visceral pericardium and to the anterior mediastinal tissue.

Both ventricles were dilated. The left ventricle showed some hypertrophy, but there was marked thinning at the tip of the left ventricle and at the lower portion of the interventricular septum. In this area, the ventricular wall was only $2 \mathrm{~mm}$. in thickness. At the lower end of the interventricular septum, and near the apex, there was a rupture measuring $3 \mathrm{~mm}$. in diameter. The valves showed no gross abnormality. The coronary arteries were atheromatous, and the descending branch of the left coronary artery showed marked atheroma with diminution of its lumen, and its lower half was occluded by an organizing thrombus.

On histological examination the thinned part of the ventricle was infarcted and infiltrated with acute inflammatory cells, and showed very little fibrosis. The heart muscle in this area was necrotic.

\section{Case 2}

A man, aged 65, was seen at home. Eighteen hours previously he had felt severe pain across the lower sternum, passing down both arms and up into the throat. He vomited repeatedly but had had no dyspnœa.

Clinically he was pale and shocked, and the heart sounds were very muffled with a loud systolic murmur audible all over the præcordium, maximal in the fourth left interspace, internal to the nipple line. The heart rate was irregular at 84 and the blood pressure 85/65. He had been seen with a chest infection two years previously when the heart sounds were normal and blood pressure 180/85.

An electrocardiogram showed evidence of a massive infarction with heart block (Fig. 2). He was diagnosed as myocardial infarction and in view of the intensity of the murmur, and the knowledge that this was not present previously, he was thought to have a ruptured interventricular septum.
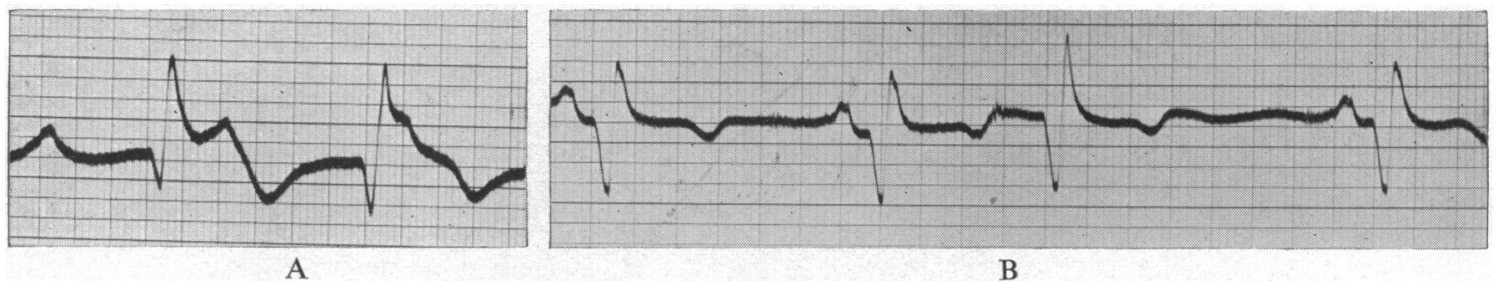

FIG. 2.-From Case 2 showing posterior cardiac infarction. (A) On admission about one day after the onset. (B) Eight days later, shortly before his death.

His condition was such that he was not admitted to hospital until three days later, but he made very little progress. He became disorientated, his pain recurred, and his blood pressure remained in the neighbourhood of $85 / 65$. The intensity of the murmur was more pronounced but at no stage did he develop signs of congestive failure. He died eight days after his original infarction.

Necropsy. There was a fibrinous pericarditis over the posterior wall of the heart. The right ventricle was dilated. There was an area of infarction over the posterior wall of the left ventricle and involving the posterior edge of the interventricular septum. In this area, the myocardium was thin, and friable and bulged outwards. Where the septum met the posterior wall, there was a linear rupture about $1 \mathrm{~cm}$. in length so that the right ventricle was in direct communication with the left ventricle. There was some adherent ante-mortem clot over the infarcted area. The heart valves were normal. The coronary arteries showed some sclerosis, but were not dissected along their lengths as the heart was preserved as a specimen.

\section{Summary}

Two patients are described in whom coronary thrombosis led to rupture of the interventricular septum. In one who survived for fifteen days the infarct was silent. In the other who survived for eight days the rupture occurred within 16 hours of the original infarction. 